\title{
Augmentation of the ubiquitin-mediated proteolytic system by F-box and additional motif-containing proteins (Review)
}

\author{
KAZUYUKI SATO and KENICHI YOSHIDA \\ Department of Life Sciences, School of Agriculture, Meiji University, Kawasaki, Kanagawa, Japan
}

Received July 6, 2010; Accepted August 19, 2010

DOI: 10.3892/ijo_00000758

\begin{abstract}
Cells are tightly regulated by sophisticated systems. Among such systems, post-translational modification has been intensively studied, and the ubiquitin-proteasome system is one of the best-known proteolytic mechanisms for the timely destruction of regulatory proteins. As progress has been made in research on the ubiquitin-proteasome system, our understanding of fundamental regulatory circuits, such as the cell cycle and circadian rhythms, has progressed. Here, we focused on the SKP1-CUL1-F-box protein of E3 ubiquitin ligase, especially the F-box and additional characteristic domain-containing proteins, as adaptors for regulatory proteins. Accumulating evidence suggests that the F-box and additional characteristic domain-containing proteins are involved in a wide variety of cellular processes and pathogenesis. This raises the possibility that F-box and additional characteristic domain-containing proteins could be used as biomarkers for certain diseases.
\end{abstract}

\section{Contents}

1. Introduction

2. F-box and LRR-containing proteins

3. F-box and WD40 domain-containing proteins

4. Future perspectives

\section{Introduction}

The rapid activation and degradation of regulatory proteins that are involved in critical pathways, such as signal trans-

Correspondence to: Dr Kenichi Yoshida, Department of Life Sciences, School of Agriculture, Meiji University, 1-1-1 Higashimita, Tama-ku, Kawasaki, Kanagawa 214-8571, Japan

E-mail: yoshida@isc.meiji.ac.jp

Abbreviations: APC/C, anaphase-promoting complex or cyclosome; LRR, leucine-rich repeat; SCF, SKP1-CUL1-F-box protein; WD, tryptophan-aspartic acid

Key words: F-box, SKP1-CUL1-F-box protein, ubiquitin duction and the cell cycle, are essential for determining the proper destinations of cells (1). Among post-translational modifications, phosphorylation and dephosphorylation are classical modifications that are recognized as important switches for quick responses to and the termination of stimuli (2). Another crucial system is the ubiquitin-proteasome, an ATP-dependent ubiquitin-mediated proteolytic system that is widely recognized in a variety of organisms and plays a pivotal role in timely ubiquitination and the typical degradation of regulatory proteins that are basically phosphorylated (3). As an example of the ubiquitin-proteasome system, the SKP1-CUL1-F-box protein (SCF) and the anaphase-promoting complex or cyclosome (APC/C) have been intensively analyzed and are considered to be the most important E3 ubiquitin ligases for the regulation of cell growth and proliferation $(4,5)$, and SCF is the best understood example to be implicated in tumorigenesis $(6,7)$. The molecular dissection of SCF complexes has revealed that they are basically composed of 3 key components: i) SKP1, also known as p19, an adaptor protein between the core ubiquitin ligase and F-box proteins, ii) the core ubiquitin ligase, which consists of CUL1 (a scaffold protein for SKP1 and the F-box proteins described hereafter), RING-finger protein RBX1 (also known as ROC1) and the E2 ubiquitin-conjugating enzyme CDC34, and iii) F-box proteins, which have an F-box motif of $\sim 40$ amino acids, are responsible for the association with SKP1, and generally possess additional domains that can interact with a wide variety of proteins for ubiquitination (Fig. 1). Therefore, the specificity of regulatory proteins that are to be destroyed by a ubiquitin-mediated proteolytic system is largely determined at the level of substrate recognition, which is mediated by the F-box proteins $(8,9)$. So far, large numbers of F-box proteins have been identified as binding partners of SKP1 $(10,11)$ or with sequence homology in mammals (12). Several hundreds of F-box proteins have also been identified in plants (13).

The human F-box only protein 1 (FBXO1 or FBX1) was first identified as cyclin $\mathrm{F}$, which is homologous with cycles $\mathrm{A}$ and $\mathrm{B}$, but was later shown to form a complex with SKP1 through an F-box motif, thus linking the cell cycle to ubiquitin proteolysis (14). FBXO is known to be involved in disease and the ubiquitination of important regulatory proteins during the cell cycle. For example, FBXO31, a candidate tumor suppressor in breast cancer, has been revealed to be under the control of DNA damage signaling, a component of SCF ubiquitin ligase, and a mediator of the degradation of cyclin D1 $(15,16)$. FBXO32 has been independently identified by 
two studies, as its expression has been shown to change in a muscle atrophy model $(17,18)$. This raises the possibility that F-box proteins could be used as biomarkers for certain diseases. Unlike FBXO, which only has an F-box motif, leucine-rich repeats (LRRs) such as FBXL1 (also known as SKP2 or p45), or tryptophan-aspartic acid 40 (WD40) repeats such as FBXW1 (also known as the ß-transducin repeatcontaining protein) have also been recognized in addition to the F-box motif. Now, F-box proteins are characterized based on their characteristic domains: FBXL, where L means LRRs; FBXW, where $\mathrm{W}$ means the WD40 domain; and FBXO, where $\mathrm{O}$ means others.

In this review, the emphasis is on the recent findings of F-box proteins with additional motifs in ubiquitin-mediated proteolysis as well as in other cellular machinery and the pathogenesis of certain diseases.

\section{F-box and LRR-containing proteins}

So far, 22 members of FBXL proteins have been identified (Table I). FBXL1, was one of the first F-box and LRR-containing proteins involved in ubiquitin-mediated proteolysis to be identified, and together with SKP1, were initially regarded as $\mathrm{S}$ phase kinase-associated proteins, namely interactors of cyclin $\mathrm{A} / \mathrm{CDK} 2$, and have thus been implicated in the regulation of cell cycle control, especially in the entry and maintenance of the S phase in human cells (19). Thereafter, SKP1 and FBXL1 were shown to associate with CUL1, and this protein complex was shown to be capable of functioning as an E3 ligase targeting important regulators of the cell cycle in a selective manner. Other than cyclin A/CDK2, FBXL1 has been shown to target the phosphorylated CDK inhibitor p27Kip1 for ubiquitination and degradation $(20,21)$. This tight regulation is considered to be an important mechanism for safeguarding against tumorigenesis (22). In addition to p27Kip1, cyclin E was identified as a FBXL1 target based on data obtained from studies using FBXL1knockout mice (23). At present, cyclin D and the CDK inhibitors, p21Cip1 and p57Kip2, as well as p130, Tob1 and ING3 have all been identified as targets for ubiquitindependent protein degradation via FBXL1. Thus, FBXL1 is highly likely to be important for proper cell cycle regulation and tumor-suppressive mechanisms $(24,25)$. The phosphorylation of FBXL1 by AKT has been shown to be critical for SCF complex formation and E3 ligase activity (26). FBXL1 itself is poly-ubiquitinated for degradation during the $\mathrm{G} 1$ phase, and this is mediated by the ubiquitin ligase, APC/C, and its activator, CDH1 (27).

FBXL2, which has a CAAX motif (CVIL) in addition to an F-box domain, can be geranylgeranylated and is associated with the nonstructural protein 5A (NS5A) of the hepatitis C virus ( $\mathrm{HCV}$ ), and this association has been shown to be crucial for HCV RNA replication (28). The F-box of FBXL2 is not required for the association with NS5A, but the depletion of the F-box resulted in the suppression of $\mathrm{HCV}$ RNA replication (28).

A subset of FBXL has been implicated in the regulation of the circadian clock. Among the tested members including FBXL1, FBXL3, FBXL10 and FBXL11, only FBXL3 has been shown to bind with the circadian photoreceptor crypto-

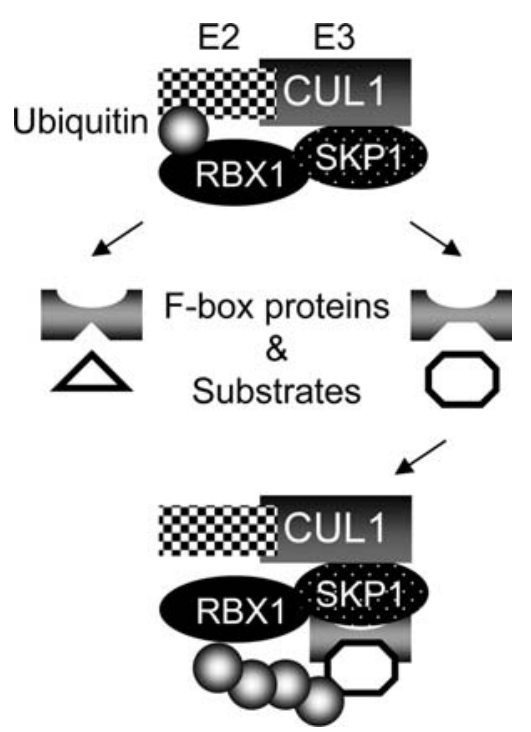

Figure 1. SCF complex. E3 recruits the F-box protein through SKP1, and the substrates captured by the F-box protein are then ubiquitinated for degradation.

chromes CRY1 and CRY2, which are downstream targets and simultaneously act as negative regulators of the CLOCKBMAL1 heterodimeric transcription factor (29). Together with the results observed in FBXL3-inactivated mice, which exhibit a slower circadian clock, these findings indicate that FBXL3 controls the oscillations of the circadian clock in mammals as an ubiquitin ligase (29-31). In Drosophila, light stimuli promote the binding of CRY to Timeless, and this leads to the subsequent ubiquitination and degradation of Timeless via the ubiquitin-proteasome pathway (32). The Drosophila mutant of Jetlag, which is a human FBXL15 homolog, resulted in aberrant circadian rhythms, and Jetlag promoted the ubiquitination of Timeless in cultured cells (33). FBXL21 has also been shown to bind to CRY1 for degradation (34). These findings indicate the involvement of FBXL in the circadian clock regulation as well as cell cycle control.

Two independent studies have reported that FBXL5 is uniquely involved in the iron-dependent ubiquitination and degradation of the iron regulatory protein 2 , and the degradation of FBXL5 itself is controlled through its N-terminal iron-binding hemerythrin-like domain upon iron depletion $(35,36)$.

FBXL10 has been shown to have an additional domain other than the C-terminal F-box and 8 LRRs, the N-terminal JmjC, the central zinc finger and PHD domains. FBXL10 was identified as a putative tumor suppressor during the search for tumor suppressors using insertional mutagenesis in Blm-deficient mice (37). FBXL10 is involved in the transcriptional repression of certain genes. FBXL10 can interact with Jun, and this enables FBXL10 to bind to the Jun promoter, and then FBXL10 recruits transcription repressors through the zinc finger domain. Under ultraviolet (UV) damage, FBXL10 was down-regulated, inducing Jun expression and leading to cell cycle progression and UV-induced apoptosis (38). In addition, FBXL10 represses the transcription of ribosomal RNA genes via the JmjC domain (39). Similar to 
Table I. FBXL proteins and their F-box motif.

\begin{tabular}{|c|c|c|c|}
\hline FBXL & $\begin{array}{c}\text { Chromosomal } \\
\text { location }\end{array}$ & $\begin{array}{l}\text { Amino } \\
\text { acid } \\
\text { length }\end{array}$ & F-box motif \\
\hline FBXL1 & $5 \mathrm{p} 13$ & 424 aa & GVSWDSLPDELLLGIFSCLCLPELLKVSGVCKRWYRLASDESLWQTL \\
\hline FBXL2 & $3 \mathrm{p} 22.3$ & 423 aa & GLINKKLPKELLLRIFSFLDIVTLCRCAQISKAWNILALDGSNWQRI \\
\hline FBXL3 & $13 q 22$ & 428 aa & CDWGNLLQDIILQVFKYLPLLDRAHASQVCRNWNQVFHMPDLWRCFEF \\
\hline FBXL4 & 6q16.1 & 621 aa & NGYFDKLPYELIQLILNHLTLPDLCRLAQTCKLLSQHCCDPLQYIHLNLQPYWAKL \\
\hline FBXL5 & $4 \mathrm{p} 15.33$ & 691 aa & STGITHLPPEVMLSIFSYLNPQELCRCSQVSMKWSQLTKTGSLWKHL \\
\hline FBXL6 & $8 \mathrm{q} 24.3$ & 539 aа & RRRARAAPRPRSAEDWWWDRLAPRGSGYHLLQSDSMLLVLSEPGPARPRAQRRASRRTPR \\
\hline FBXL7 & $5 \mathrm{p} 15.1$ & 491 aa & QASIDRLPDHSMVQIFSFLPTNQLCRCARVCRRWYNLAWDPRLWRTI \\
\hline FBXL8 & $16 \mathrm{q} 22.1$ & 374 aa & AEPGEGLPEEVLALIFRHLSLRDRAAAARVCRAWAAAATCSAVWHDT \\
\hline FBXL9 & $16 \mathrm{q} 22.1$ & 223 aa & SHCSRLSDKGWAQAASSWPRLQHLNLSSCSQLIEQTLDAIGQACRQLR \\
\hline FBXL10 & $12 \mathrm{q} 24.31$ & 1336 aa & DGAAHVMHREVWMAVFSYLSHQDLCVCMRVCRTWNRWCCDKRLWTRI \\
\hline FBXL11 & $11 \mathrm{q} 13.1$ & 1162 aа & DESWMQREVWMSVFRYLSRRELCECMRVCKTWYKWCCDKRLWTKIDLS \\
\hline FBXL12 & $19 \mathrm{p} 13.2$ & 326 aа & MATLVELPDSVLLEIFSYLPVRDRIRISRVCHRWKRLVDDRWLWRHV \\
\hline FBXL13 & $7 \mathrm{q} 22.1$ & 735 aa & KCDISLLPERAILQIFFYLSLKDVIICGQVNHAWMLMTQLNSLWNAI \\
\hline FBXL14 & $12 \mathrm{p} 13.33$ & 418 aa & ETHISCLFPELLAMIFGYLDVRDKGRAAQVCTAWRDAAYHKSVWRGV \\
\hline FBXL15 & $10 \mathrm{q} 24.32$ & 300 aa & FLDLPWEDVLLPHVLNRVPLRQLLRLQRVSRAFRSLVQLHLAGLRRFD \\
\hline FBXL16 & $16 \mathrm{p} 13.3$ & 479 aа & PLATDEKILNGLFWYFSACEKCVLAQVCKAWRRVLYQPKFWAGLTP \\
\hline FBXL17 & $5 q 21.3$ & 701 aa & TPDINQLPPSILLKIFSNLSLDERCLSASLVCKYWRDLCLDFQFWKQL \\
\hline FBXL18 & $7 \mathrm{p} 22.2$ & 718 aа & GVHLLGFSDEILLHILSHVPSTDLILNVRRTCRKLAALCLDKSLIHTV \\
\hline FBXL19 & $16 \mathrm{p} 11.2$ & 694 aa & AGSDHPLPRAAWLRVFQHLGPRELCICMRVCRTWSRWCYDKRLWPRM \\
\hline FBXL20 & $17 \mathrm{q} 21.2$ & 436 aа & AVINKKLPKELLLRIFSFLDVVTLCRCAQVSRAWNVLALDGSNWQRI \\
\hline FBXL21 & $5 q 31$ & 434 aa & LLDWGSLPHHVVLQIFQYLPLLDRACASSVCRRWNEVFHISDLWRKF \\
\hline FBXL22 & $15 q 22.1$ & 241 aa & MHITQLNRECLLHLFSFLDKDSRKSLARTCSQLHDVFEDPALWSLL \\
\hline
\end{tabular}

Chromosomal locations and amino acid lengths are shown. The F-box motif was predicted using UniProt information.

FBXL10, FBXL11 contains an N-terminal JmjC domain, central zinc finger and PHD domains as well as a C-terminal F-box and 8 LRRs. The JmjC domain of FBXL11 has been shown to demethylase activity towards histone $\mathrm{H} 3$ at lysine 36 , which is important for chromatin dynamics and transcription (40). Collectively, FBXL proteins containing the $\mathrm{JmjC}$ domain have been strongly implicated in the regulation of transcription responsible for the proper regulation of cell proliferation and cancer development. Among the FBXL proteins, FBXL10 and FBXL11 are extraordinarily large (Table I). Based on the multiple sequence alignment executed by ClustalW analysis using full-length and F-box motif amino acids, it is predicted that FBXL10 and FBXL11 are the ones most closely related to each other (Fig. 2). This raises the possibility that amino acid comparisons could be useful for predicting the function of uncharacterized F-box proteins.

Two mRNAs for FBXL13 have been reported in leukemia cell lines to have 5 and 12 LRRs, respectively (41), suggesting possible differences in binding partners or affinities. Together with FBXW1, FBXL14 was identified as being involved in the ubiquitination and proteasome degradation of SNAIL1, a master regulator of the epithelial to mesenchymal transition. This process occurs independently of phosphorylation by GSK-3ß and during hypoxia (42). We recently identified
FBXL16 as an E2F1-regulated gene (43). FBXL17 has been shown to bind to the ribonucleotide reductase M2 (RRM2) subunit to promote RRM2 overexpression in the breast cancer cell line, MCF-7 (44). Mouse FBXL20, known as Scrapper, has been shown to be localized in a specific region of the brain and to be essential for RIM1 degradation for synaptic tuning (45).

\section{F-box and WD40 domain-containing proteins}

FBXW1 was originally identified as a human immunodeficiency virus type 1 (HIV-1) Vpu interactor, and this interaction enables CD4 degradation in the endoplasmic reticulum by proteasome (46). FBXW1 is composed of the N-terminal F-box and the C-terminal 7 WD40 repeats. The former binds to SKP1 and the latter to Vpu. The phosphorylation of target proteins is the key step for FBXW1-mediated ubiquitination and degradation (47). The nuclear factor $\kappa-\mathrm{B}(\mathrm{NF}-\kappa \mathrm{B})$ activation requires the phosphorylation of the $N F-\kappa B$ inhibitor IKB- $\alpha$ (IKBA). FBXW1 has been shown to have a unique role in IKBA ubiquitination and destruction in the proteasome when IKBA is phosphorylated (48). In addition to NF- $\mathrm{BB}$ signaling, FBXW1 has also been implicated in the regulation of WNT signaling (3). The phosphorylation-dependent ubiquitination of Claspin by SCFs containing FBXW1, is an 
Full length

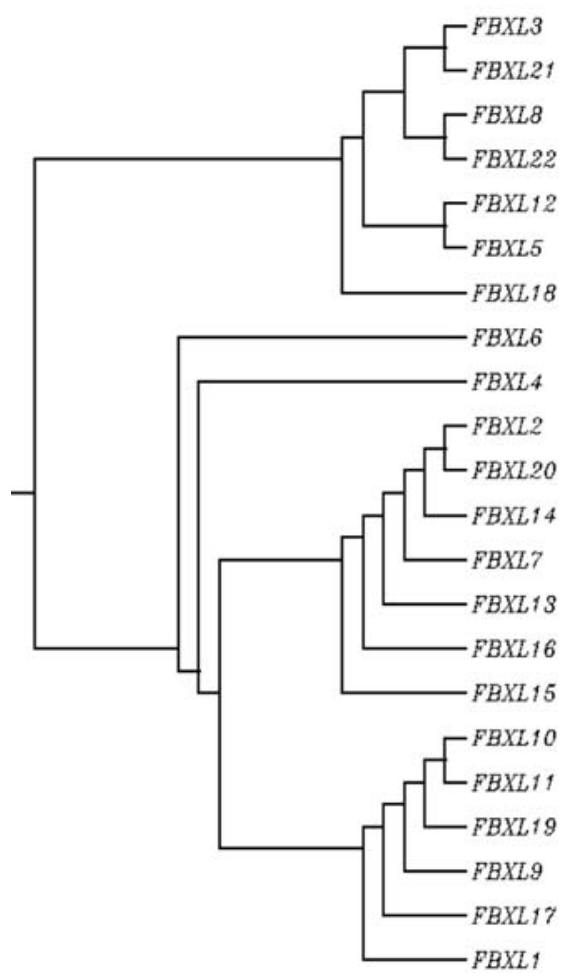

$\mathrm{F}$ box

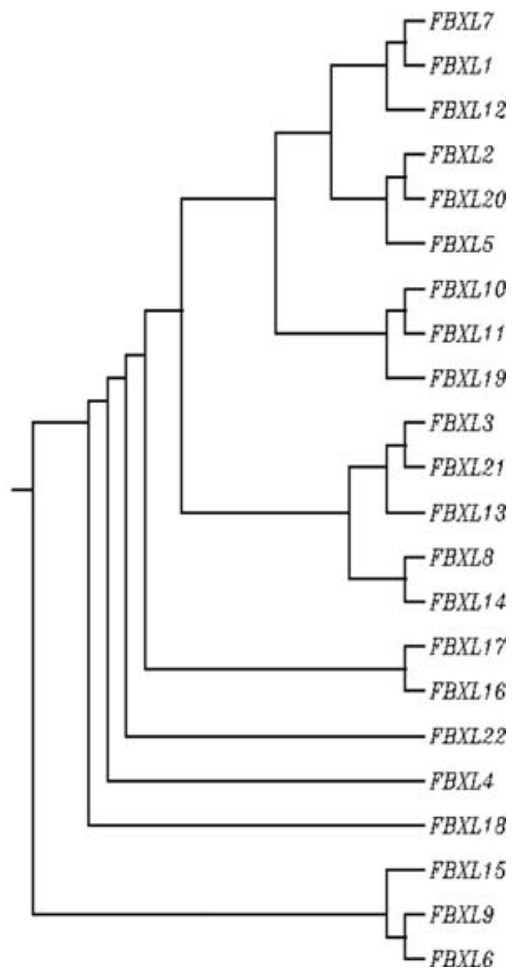

Figure 2. Neighbor-joining tree of FBXL proteins. Full-length (left) and F-box motif (right) amino acids are used for multiple sequence alignment using ClustalW analysis.

important mechanism for Claspin degradation coinciding with the onset of mitosis and also the proper execution of checkpoint machinery (49,50). In Drosophila, FBXW1 has been asssociated with phosphorylated Period, a circadian clock regulator, for ubiquitin-mediated proteolysis (51).

FBXW2 has been shown to interact with CUL1 and SKP1 but not with CUL2 (11). FBXW4 was identified in mouse mutant dactylaplasia lacking hands and feet by positional cloning (52). FBXW7 was originally identified in Drosophila as Archipelago, which interacts with cyclin E. Mutation in Archipelago resulted in the persistent up-regulation of cyclin E (53). Based on accumulating reports that FBXW7 mediates the degradation of cyclin E, Notch, Jun and Myc, FBXW7 could be a tumor suppressor gene (54).

As a scaffold for F-box proteins, the diversity in CUL has been reported. For example, CUL7 has been found to act as an interactor of RBX1. Unlike CUL1, which binds to SKP1, CUL7 has been associated with a complex containing SKP1 and FBXW8, but not with SKP1 alone (55). TSC2, which is a responsible gene for tuberous sclerosis (TSC), has been shown to be recruited by FBXW5 to CUL4-DDB1, a large ß-propeller protein and recruiter for the WD40, -ROC1 E3 ubiquitin ligase (56). The CUL4-DDB1 ubiquitin ligases have been associated with multiple WD40-containing proteins and the regulation of chromatin functions, such as DNA replication, transcription, and histone modification $(57,58)$. FBXW9, 10, 11, 12 have been identified, but their involvement in ubiquitin-mediated proteolysis has not yet been reported.

\section{Future perspectives}

Spatial regulation of the cell cycle by the coupling of SCF and $\mathrm{APC} / \mathrm{C}$ is an important example for understanding the complex molecular mechanisms executed by E3 ubiquitin ligases. SCF and APC/C are responsible for the ubiquitination of regulatory protein function in the G1 to G2 phases and mainly the $\mathrm{M}$ phase, respectively (59). There are 2 structural types of ubiquitin ligases: RING-finger and HECTdomain type proteins. SCF and $\mathrm{APC} / \mathrm{C}$ are characterized as RING-finger types. The diversity of the CUL family, which acts as a scaffold for RING-finger type proteins, should be noted. Uniquely, SCF and APC/C are not involved in the regulation of $\mathrm{p} 53$ and $\mathrm{pRb}$. This raises the possibility that SCF and APC/C could have evolved as fundamental cell cycle regulators of the basic cell cycle machinery. However, high-order regulation of the genome, such as the maintenance of genome stability, which is critical for protection against tumorigenesis, is unique to multi-cellular organisms where additional E3 ubiquitin ligases have evolved. In conclusion, the ubiquitin-proteasome system is considered to have evolved simultaneously with the acquisition of high-order functions in organisms.

\section{References}

1. Krek W: Proteolysis and the G1-S transition: the SCF connection. Curr Opin Genet Dev 8: 36-42, 1998.

2. Boulikas T: Phosphorylation of transcription factors and control of the cell cycle. Crit Rev Eukaryot Gene Expr 5: 1-77, 1995. 
3. Maniatis T: A ubiquitin ligase complex essential for the NFkappaB, Wnt/Wingless, and Hedgehog signaling pathways. Genes Dev 13: 505-510, 1999.

4. Vodermaier HC: APC/C and SCF: controlling each other and the cell cycle. Curr Biol 14: R787-R796, 2004.

5. Skaar JR and Pagano M: Control of cell growth by the SCF and APC/C ubiquitin ligases. Curr Opin Cell Biol 21: 816-824, 2009

6. Nakayama KI and Nakayama K: Regulation of the cell cycle by SCF-type ubiquitin ligases. Semin Cell Dev Biol 16: 323-333, 2005.

7. Nakayama KI and Nakayama K: Ubiquitin ligases: cell-cycle control and cancer. Nat Rev Cancer 6: 369-381, 2006.

8. Craig KL and Tyers M: The F-box: a new motif for ubiquitin dependent proteolysis in cell cycle regulation and signal transduction. Prog Biophys Mol Biol 72: 299-328, 1999.

9. Cardozo T and Pagano M: The SCF ubiquitin ligase: insights into a molecular machine. Nat Rev Mol Cell Biol 5: 739-751, 2004 .

10. Winston JT, Koepp DM, Zhu C, Elledge SJ and Harper JW: A family of mammalian F-box proteins. Curr Biol 9: 1180-1182, 1999.

11. Cenciarelli C, Chiaur DS, Guardavaccaro D, Parks W, Vidal M and Pagano M: Identification of a family of human F-box proteins. Curr Biol 9: 1177-1179, 1999.

12. Jin J, Cardozo T, Lovering RC, Elledge SJ, Pagano M and Harper JW: Systematic analysis and nomenclature of mammalian F-box proteins. Genes Dev 18: 2573-2580, 2004.

13. Lechner E, Achard P, Vansiri A, Potuschak T and Genschik P: Fbox proteins everywhere. Curr Opin Plant Biol 9: 631-638, 2006.

14. Bai C, Sen P, Hofmann K, et al: SKP1 connects cell cycle regulators to the ubiquitin proteolysis machinery through a novel motif, the F-box. Cell 86: 263-274, 1996.

15. Santra MK, Wajapeyee $\mathrm{N}$ and Green MR: F-box protein FBXO31 mediates cyclin D1 degradation to induce G1 arrest after DNA damage. Nature 459: 722-725, 2009

16. Kumar R, Neilsen PM, Crawford J, et al: FBXO31 is the chromosome 16q24.3 senescence gene, a candidate breast tumor suppressor, and a component of an SCF complex. Cancer Res 65: 11304-11313, 2005

17. Bodine SC, Latres E, Baumhueter S, et al: Identification of ubiquitin ligases required for skeletal muscle atrophy. Science 294: 1704-1708, 2001

18. Gomes MD, Lecker SH, Jagoe RT, Navon A and Goldberg AL: Atrogin-1, a muscle-specific F-box protein highly expressed during muscle atrophy. Proc Natl Acad Sci USA 98: 14440-14445, 2001

19. Zhang H, Kobayashi R, Galaktionov K and Beach D: p19Skp1 and p45Skp2 are essential elements of the cyclin A-CDK2 S phase kinase. Cell 82: 915-925, 1995.

20. Carrano AC, Eytan E, Hershko A and Pagano M: SKP2 is required for ubiquitin-mediated degradation of the $C D K$ inhibitor p27. Nat Cell Biol 1: 193-199, 1999.

21. Montagnoli A, Fiore F, Eytan E, et al: Ubiquitination of p27 is regulated by $\mathrm{Cdk}$-dependent phosphorylation and trimeric complex formation. Genes Dev 13: 1181-1189, 1999.

22. Bloom J and Pagano M: Deregulated degradation of the cdk inhibitor p27 and malignant transformation. Semin Cancer Biol 13: 41-47, 2003

23. Nakayama K, Nagahama H, Minamishima YA, et al: Targeted disruption of Skp2 results in accumulation of cyclin $\mathrm{E}$ and p27(Kip1), polyploidy and centrosome overduplication. EMBO J 19: 2069-2081, 2000.

24. Yu ZK, Gervais JL and Zhang H: Human CUL-1 associates with the SKP1/SKP2 complex and regulates p21(CIP1/WAF1) and cyclin D proteins. Proc Natl Acad Sci USA 95: 11324-11329, 1998.

25. Kitagawa K, Kotake Y and Kitagawa M: Ubiquitin-mediated control of oncogene and tumor suppressor gene products. Cancer Sci 100: 1374-1381, 2009

26. Lin HK, Wang G, Chen Z, et al: Phosphorylation-dependent regulation of cytosolic localization and oncogenic function of Skp2 by Akt/PKB. Nat Cell Biol 11: 420-432, 2009.

27. Wei W, Ayad NG, Wan Y, Zhang GJ, Kirschner MW and Kaelin WG Jr: Degradation of the SCF component Skp2 in cellcycle phase G1 by the anaphase-promoting complex. Nature 428: 194-198, 2004

28. Wang C, Gale M Jr, Keller BC, et al: Identification of FBL2 as a geranylgeranylated cellular protein required for hepatitis $\mathrm{C}$ virus RNA replication. Mol Cell 18: 425-434, 2005.
29. Busino L, Bassermann F, Maiolica A, et al: SCFFbx13 controls the oscillation of the circadian clock by directing the degradation of cryptochrome proteins. Science 316: 900-904, 2007.

30. Godinho SI, Maywood ES, Shaw L, et al: The after-hours mutant reveals a role for Fbx13 in determining mammalian circadian period. Science 316: 897-900, 2007

31. Siepka SM, Yoo SH, Park J, et al: Circadian mutant Overtime reveals F-box protein FBXL3 regulation of cryptochrome and period gene expression. Cell 129: 1011-1023, 2007.

32. Lin FJ, Song W, Meyer-Bernstein E, Naidoo N and Sehgal A: Photic signaling by cryptochrome in the Drosophila circadian system. Mol Cell Biol 21: 7287-7294, 2001.

33. Koh K, Zheng X and Sehgal A: JETLAG resets the Drosophila circadian clock by promoting light-induced degradation of TIMELESS. Science 312: 1809-1812, 2006.

34. Dardente H, Mendoza J, Fustin JM, Challet E and Hazlerigg DG: Implication of the F-Box Protein FBXL21 in circadian pacemaker function in mammals. PLoS One 3: e3530, 2008.

35. Vashisht AA, Zumbrennen KB, Huang X, et al: Control of iron homeostasis by an iron-regulated ubiquitin ligase. Science 326: 718-721, 2009.

36. Salahudeen AA, Thompson JW, Ruiz JC, et al: An E3 ligase possessing an iron-responsive hemerythrin domain is a regulator of iron homeostasis. Science 326: 722-726, 2009.

37. Suzuki T, Minehata K, Akagi K, Jenkins NA and Copeland NG: Tumor suppressor gene identification using retroviral insertional mutagenesis in Blm-deficient mice. EMBO J 25: 3422-3431, 2006.

38. Koyama-Nasu R, David G and Tanese N: The F-box protein Fbl10 is a novel transcriptional repressor of c-Jun. Nat Cell Biol 9: 1074-1080, 2007.

39. Frescas D, Guardavaccaro D, Bassermann F, Koyama-Nasu R and Pagano M: JHDM1B/FBXL10 is a nucleolar protein that represses transcription of ribosomal RNA genes. Nature 450: 309-313, 2007

40. Tsukada Y, Fang J, Erdjument-Bromage H, et al: Histone demethylation by a family of JmjC domain-containing proteins. Nature 439: 811-816, 2006.

41. Curtiss NP, Bonifas JM, Lauchle JO, et al: Isolation and analysis of candidate myeloid tumor suppressor genes from a commonly deleted segment of 7q22. Genomics 85: 600-607, 2005.

42. Viñas-Castells R, Beltran M, Valls G, et al: The hypoxiacontrolled FBXL14 ubiquitin ligase targets SNAIL1 for proteasome degradation. J Biol Chem 285: 3794-3805, 2010.

43. Sato K, Kusama Y, Tategu M and Yoshida K: FBXL16 is a novel E2F1-regulated gene commonly upregulated in p16INK4A- and p14ARF-silenced HeLa cells. Int J Oncol 36: 479-490, 2010.

44. Xiao GG, Zhou BS, Somlo G, et al: Identification of Fbox/LLR-repeated protein 17 as potential useful biomarker for breast cancer therapy. Cancer Genomics Proteomics 5: 151-160, 2008.

45. Yao I, Takagi H, Ageta H, et al: SCRAPPER-dependent ubiquitination of active zone protein RIM1 regulates synaptic vesicle release. Cell 130: 943-957, 2007.

46. Margottin F, Bour SP, Durand H, et al: A novel human WD protein, h-beta TrCp, that interacts with HIV-1 Vpu connects CD4 to the ER degradation pathway through an F-box motif. Mol Cell 1: 565-574, 1998.

47. Karin M and Ben-Neriah Y: Phosphorylation meets ubiquitination: the control of NF-[kappa]B activity. Annu Rev Immunol 18: 621-663, 2000

48. Yaron A, Hatzubai A, Davis M, et al: Identification of the receptor component of the IkappaBalpha-ubiquitin ligase. Nature 396: 590-594, 1998.

49. Mailand N, Bekker-Jensen S, Bartek J and Lukas J: Destruction of Claspin by SCFbetaTrCP restrains Chk1 activation and facilitates recovery from genotoxic stress. Mol Cell 23: 307-318, 2006.

50. Peschiaroli A, Dorrello NV, Guardavaccaro D, et al: SCFbetaTrCP-mediated degradation of Claspin regulates recovery from the DNA replication checkpoint response. Mol Cell 23: 319-329, 2006.

51. Ko HW, Jiang J and Edery I: Role for Slimb in the degradation of Drosophila Period protein phosphorylated by Doubletime. Nature 420: 673-678, 2002.

52. Sidow A, Bulotsky MS, Kerrebrock AW, et al: A novel member of the F-box/WD40 gene family, encoding dactylin, is disrupted in the mouse dactylaplasia mutant. Nat Genet 23: 104-107, 1999. 
53. Moberg KH, Bell DW, Wahrer DC, Haber DA and Hariharan IK Archipelago regulates Cyclin E levels in Drosophila and is mutated in human cancer cell lines. Nature 413: 311-316, 2001.

54. Welcker M and Clurman BE: FBW7 ubiquitin ligase: a tumour suppressor at the crossroads of cell division, growth and differentiation. Nat Rev Cancer 8: 83-93, 2008.

55. Dias DC, Dolios G, Wang R and Pan ZQ: CUL7: A DOC domain-containing cullin selectively binds Skp1.Fbx29 to form an SCF-like complex. Proc Natl Acad Sci USA 99: 1660116606, 2002.

56. Hu J, Zacharek S, He YJ, et al: WD40 protein FBW5 promotes ubiquitination of tumor suppressor TSC2 by DDB1-CUL4ROC1 ligase. Genes Dev 22: 866-871, 2008.
57. O'Connell BC and Harper JW: Ubiquitin proteasome system (UPS): what can chromatin do for you? Curr Opin Cell Biol 19: 206-214, 2007.

58. Higa LA, Wu M, Ye T, Kobayashi R, Sun $\mathrm{H}$ and Zhang $\mathrm{H}$ : CUL4-DDB1 ubiquitin ligase interacts with multiple WD40repeat proteins and regulates histone methylation. Nat Cell Biol 8: 1277-1283, 2006.

59. Frescas D and Pagano M: Deregulated proteolysis by the F-box proteins SKP2 and beta-TrCP: tipping the scales of cancer. Nat Rev Cancer 8: 438-449, 2008. 